\title{
Emergent Constraints for Cloud Feedbacks
}

\author{
Stephen A. Klein ${ }^{1} \cdot$ Alex Hall $^{2}$
}

Published online: 26 October 2015

(C) Springer International Publishing AG 2015

\begin{abstract}
Emergent constraints are physically explainable empirical relationships between characteristics of the current climate and long-term climate prediction that emerge in collections of climate model simulations. With the prospect of constraining long-term climate prediction, scientists have recently uncovered several emergent constraints related to long-term cloud feedbacks. We review these proposed emergent constraints, many of which involve the behavior of low-level clouds, and discuss criteria to assess their credibility. With further research, some of the cases we review may eventually become confirmed emergent constraints, provided they are accompanied by credible physical explanations. Because confirmed emergent constraints identify a source of model error that projects onto climate predictions, they deserve extra attention from those developing climate models and climate observations. While a systematic bias cannot be ruled out, it is noteworthy that the promising emergent constraints suggest larger cloud feedback and hence climate sensitivity.
\end{abstract}

Keywords Emergent constraints $\cdot$ Cloud feedbacks $\cdot$ Climate models $\cdot$ Climate sensitivity

This article is part of the Topical Collection on Climate Feedbacks

Stephen A. Klein

klein21@1lnl.gov

1 Program for Climate Model Diagnosis and Intercomparison, Lawrence Livermore National Laboratory, 7000 East Avenue, L-103, Livermore, CA 94551, USA

2 Department of Atmospheric and Oceanic Sciences, University of California, Los Angeles, Los Angeles, CA, USA

\section{What Is an Emergent Constraint?}

When combined with the power of human mind to assess the physical plausibility of their predictions, comprehensive climate models are the most powerful tools available to predict future climate and its response to radiative forcings such as the anthropogenic increase in greenhouse gases. Unfortunately, model predictions for key metrics of climate change do not converge to a single value. The most prominent example is the climate sensitivity, defined as the equilibrium warming resulting from a doubling of carbon dioxide. It varies by at least a factor of 2 in the most recent collection of models used for climate change assessment [37], much as it has in all past model collections.

Especially when models diverge, scientists use their insight to assess the relative credibility of model predictions. Often, they appeal to the principle that models unable to predict past climate variations skillfully should not be trusted for future climate predictions. However, with past climate variations such as the global warming of the past century or glacial-interglacial transitions of the Pleistocene, there are uncertainties in the observed forcing as well as the response. In addition, past climate forcings differ in important ways from that resulting from changes in carbon dioxide alone. Thus, past climate variations are an incomplete lens through which to judge the credibility of a climate model's future predictions. And while they may help constrain other model responses, they do not offer the ability to appreciably narrow the range of climate sensitivity estimates beyond that of the models $[18,23,24,32]$.

The climate of the past few decades is observed well enough to characterize the mean state, variability, and trends of key climate variables such as temperature. Although less direct than verifying the models against past climate response to external forcing, a more basic principle is the idea that models failing to reproduce these statistics should not be trusted for future climate 
prediction. Past attempts following this line of reasoning typically suggest climate sensitivities between 3 and $4 \mathrm{~K}$ [17, 22, 26, 34]. But which aspect of the current climate is important for its climate prediction? It seems intuitive that realistic simulation of the current climate for variable $x$ (temperature, clouds, or something else) would lead to a more believable prediction of the change in $x$. But there is no evidence that this has to be true, and the processes shaping future response in $x$ may be quite distinct from those shaping $x$ in the current climate. For example, the water vapor, lapse rate, surface albedo, and cloud feedbacks determining climate sensitivity are not the most important processes determining the current climate's geographical and seasonal temperature distribution, a common observational target for climate model development. This raises the question as to whether there is any better way to decide which quantities of the current climate are relevant for climate change.

The so-called emergent constraints answer this question by examining the collective behavior that emerges unexpectedly in climate model ensembles such as those assembled for the third and fifth phases of the Coupled Model Intercomparison Project (CMIP) [25, 39]. Specifically, an emergent constraint is a physically explainable empirical relationship between intermodel variations in a quantity describing some aspect of recent observed climate (termed the current climate predictor and hereafter referred to as the predictor) and the intermodel variations in a future climate prediction of some quantity (the future climate predictand and hereafter referred to as the predictand). Once combined with an observational estimate of the predictor, the predictand may be constrained provided (a) the observational uncertainty does not encompass the entire intermodel spread and (b) the predictand is a single-valued function of the predictor. A constraint may be possible in the case where the observed value falls outside the range of model results, if there is sufficient confidence that the relationship between predictor and predictand holds outside the model range. This case may be of particular interest, as it indicates a systematic bias in the model ensemble.

Because the empirical relationship between predictor and predictand may be fortuitous, it should not be termed an emergent constraint unless accompanied by a plausible physical explanation. Other criteria, to be proposed below, are also important in ensuring that the physical explanation is robust. Accordingly, we divide proposals for emergent constraints into three categories: (1) "potential emergent constraints," which are simply statistical diagnoses of relationships between predictor and predictand; (2) "promising emergent constraints," for which there is also a suggested specific physical basis for the predictor-predictand relationship; and (3) "confirmed emergent constraints," for which there is evidence that the physical underpinnings of the predictorpredictand relationship are credible.

The earliest emergent constraint may be that for the snowalbedo feedback $[13,29]$. A strong linear relationship exists between (a) intermodel spread in the seasonal cycle change in surface albedo over Northern Hemisphere land per degree surface warming and (b) the change in surface albedo over Northern Hemisphere land per degree surface warming in simulations of climate warming resulting from increases in greenhouse gases (Fig. 1). Both these quantities are surrogates for snow-albedo feedback strength in their respective climate contexts. Considering an observational estimate of the seasonal cycle change, a temperature sensitivity of surface albedo in the middle range of model results would seem to be more likely. The underlying physical assumption is that the modeled processes of how land surface albedo changes with the large warming during the seasonal cycle are manifest for the smaller warming associated with climate change. Lines of evidence have been developed to support the idea that simple land surface physics are the source of model spread in this feedback. For example, in the contexts of both seasonal cycle and climate changes, the response is controlled mainly by the simulated surface albedo in snow-covered areas; models with larger albedos when snow is present produce stronger surface albedo responses in both contexts through simple thermodynamics [28]. In addition, model differences derive from nearly the same snow-covered locations in both seasonal cycle and climate change cases, eliminating the possibility that areaaveraged response could be realistic through compensating

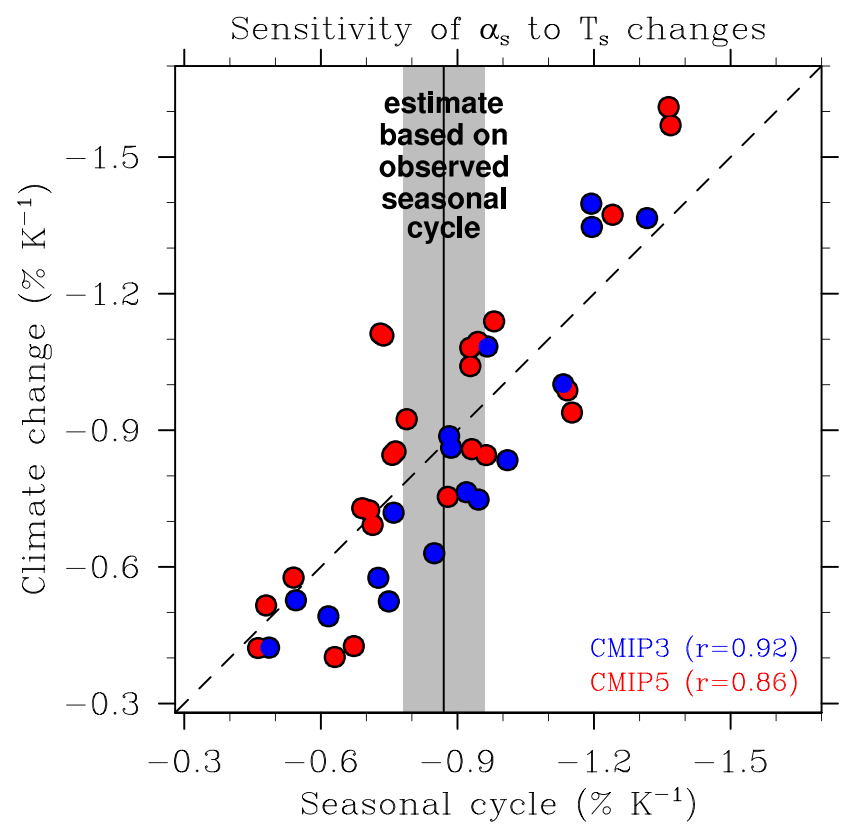

Fig. 1 Scatterplot of the change in surface albedo $\Delta \alpha_{\mathrm{s}}$ per degree of surface temperature $\Delta T_{\mathrm{s}}$ warming for Northern Hemisphere land masses in the context of climate change versus that in the context of the seasonal cycle from CMIP3 (blue circles) and CMIP5 models (red circles). The dashed line is the best-fit regression line, and the correlation coefficients for each model ensemble are indicated in the lower right corner. The thin vertical line is the observed estimate for the seasonal cycle, and the gray shading surrounding this line is the statistical uncertainty of the observed estimate. (Redrawn from [13, 29]) 
changes in different regions [29]. The available evidence supports the idea that a simple physical mechanism underpins the correlation between predictor and predictand in this case. For this reason, we label the snow-albedo feedback case a confirmed emergent constraint.

Given its overwhelming importance, climate sensitivity has proven an attractive predictand for research on emergent constraints. Since cloud feedbacks are a leading contributor to intermodel spread in climate sensitivity [37], emergent constraints for climate sensitivity necessarily include clouds either directly or indirectly. However, cloud processes are significantly more complex than that involved in snow-albedo feedback. For this reason, we begin by suggesting reliability criteria that could be used to gauge the significance and credibility of any proposed emergent constraint for cloud feedbacks. Then, we review recently proposed emergent constraints for cloud feedbacks; in doing so, we offer our subjective assessments of how well each constraint satisfies our criteria. We also discuss the conditions favoring the discovery of emergent constraints. The final section discusses the implications of emergent constraints for model development, observational science, and climate prediction.

\section{Reliability Criteria for Emergent Constraints}

With the appearance in the literature of many new potential emergent constraints for cloud feedbacks (Table 1), we need a rational way to judge whether an emergent constraint is promising or perhaps even can be confirmed or is just a fortuitous correlation without any significance. We offer the following reliability criteria as a way to apply scientific rigor to the assessment of conclusions deduced from the collective behavior of models sharing a common goal (i.e., climate simulation) but different means (i.e., cloud parameterizations).

\section{Strong Physical Basis}

Foremost is the need for a physical explanation of the empirical relationship between predictor and predictand. The physical understanding should explain in a specific manner why the predictor relates to the predictand. It should account for how differences in model structure contribute similarly to spread in the predictor and predictand. The physical understanding should also explain why the relationship exists (or does not hold) across the timescales spanning the current climate and future climate change (e.g., daily, seasonal, interannual, or interdecadal). Having a clear physical explanation will help identify whether a model matching the observed value of the predictor does so for the right reason and not through compensating errors.

The challenges here are twofold. The first is identifying a physical mechanism. Ideally, this should point to specific physical parameters, parameterizations, or their interactions. Furthermore, the physical understanding should permit quantitative explanation of intermodel variations in both predictor and predictand. Ideally, it should also be possible to assess which model parameterizations are more reliable through comparison with observations. In the case of clouds, largeeddy simulations (LES) - simulations by limited area models that resolve the fine-scale circulations forming clouds - may help with formulating a physical mechanism. However, one must be mindful that LES cannot substitute for real-world observations.

Having a hypothesized physical explanation leads to new investigations that address the second challenge of demonstrating that the physical mechanism is at work in the model ensemble. This requires either in-depth diagnostics or model experimentation or both. For diagnostics, the existing model archives are often insufficient or incomplete. For clouds, examples of necessary diagnostics include parameterizationspecific quantities such as tendencies for individual processes related to large-scale cloud microphysics and macrophysics, shallow convection, deep convection, turbulence, and largescale dynamics [27].

Direct model experimentation is a more powerful way to demonstrate whether the hypothesized physical basis of an emergent constraint correctly describes the essential physics underlying ensemble behavior. For example, if the physical explanation involves the parameterization only of a single process, current climate and climate change simulations could be performed with alterations to that parameterization. Even if a single process cannot be isolated, some support for a physical mechanism could come through testing the processes likely to be involved, such as cloud physics, convection, turbulence, or radiation. Testing can involve perturbing fixed parameters $[21,26]$ or replacing whole parameterizations in a single model $[49,55]$. Coordinated multi-model experiments such as those organized by the Cloud Feedback Model Intercomparison Project [3] disable or alter various model components, such as the parameterizations of convection or cloud radiative effects $[10,11]$. Because they sample greater model structural diversity, such experiments are potentially more valuable than those involving perturbations to a single model. Ultimately, all model experimentation is convincing only when simultaneously connected to a physical mechanism that explains how the model changes contribute similarly to intermodel variations in the predictor and predictand.

A plausible physical explanation is by far the most important criterion for an emergent constraint. However, when a physical explanation is only partially developed, the following two subsidiary criteria can also be considered, in the sense that if they are satisfied, they make it more likely that a compelling physical explanation exists. 
Table 1 Recent promising and potential emergent constraints for cloud feedbacks

\begin{tabular}{|c|c|c|c|}
\hline Reference & Current climate predictor & Future climate predictand & Primary missing factor \\
\hline \multicolumn{4}{|c|}{ Promising emergent constraints } \\
\hline Gordon and Klein [12] & $\begin{array}{l}\text { The sensitivity of extra-tropical low-level } \\
\text { cloud optical depth to temperature }\end{array}$ & $\begin{array}{l}\text { Extra-tropical low-level cloud } \\
\text { optical depth response to } \\
\text { greenhouse gas-induced } \\
\text { warming }\end{array}$ & $\begin{array}{l}\text { Clarification as to which candidate } \\
\text { physical mechanisms are dominant }\end{array}$ \\
\hline Qu et al. [30] & $\begin{array}{l}\text { The sensitivity of subtropical marine low-level } \\
\text { cloud cover to sea surface temperature }\end{array}$ & $\begin{array}{l}\text { The twenty-first century change in } \\
\text { subtropical marine low-level } \\
\text { cloud cover }\end{array}$ & $\begin{array}{l}\text { Demonstration of how the candidate } \\
\text { physical explanation accounts for } \\
\text { predictor variations }\end{array}$ \\
\hline Sherwood et al. [33] & $\begin{array}{l}\text { The strength of cloud-scale and large-scale } \\
\text { lower tropospheric mixing over oceans }\end{array}$ & Equilibrium climate sensitivity & $\begin{array}{l}\text { Demonstration that the predictor explains } \\
\text { variations in low-level clouds better } \\
\text { than equilibrium climate sensitivity }\end{array}$ \\
\hline \multicolumn{4}{|l|}{ Potential emergent constraints } \\
\hline Volodin [47] & $\begin{array}{l}\text { Difference in cloud amount between tropics } \\
\text { and southern middle latitudes }\end{array}$ & Equilibrium climate sensitivity & Credible physical explanation \\
\hline Volodin [47] & $\begin{array}{l}\text { Subtropical relative humidity in the middle } \\
\text { troposphere and the boundary layer }\end{array}$ & Equilibrium climate sensitivity & Credible physical explanation \\
\hline Trenberth and Fasullo [41] & Net radiation error for the Southern Hemisphere & Equilibrium climate sensitivity & Credible physical explanation \\
\hline Klocke et al. [21] & $\begin{array}{l}\text { Shortwave cloud radiative effect in subsidence } \\
\text { regions with moderate lower tropospheric } \\
\text { stability }\end{array}$ & Equilibrium climate sensitivity & $\begin{array}{l}\text { Credible physical explanation and } \\
\text { CMIP ensemble confirmation }\end{array}$ \\
\hline Fasullo and Trenberth [9] & $\begin{array}{l}\text { Middle tropospheric relative humidity in } \\
\text { subtropical subsidence zones }\end{array}$ & Equilibrium climate sensitivity & Credible physical explanation \\
\hline Klein et al. [20] & $\begin{array}{l}\text { Skill metric for the simulation of the climatological } \\
\text { distributions of cloud height and reflectivity }\end{array}$ & $\begin{array}{l}\text { Net and shortwave global mean } \\
\text { cloud feedback }\end{array}$ & Credible physical explanation \\
\hline Su et al. [38] & $\begin{array}{l}\text { Skill metrics for the simulation of the climatological } \\
\text { distributions of zonal mean cloud fraction and } \\
\text { relative humidity }\end{array}$ & Equilibrium climate sensitivity & Credible physical explanation \\
\hline Zhao [55] & Precipitation efficiency of moist convection & Global mean cloud feedback & CMIP ensemble confirmation \\
\hline Tian $[40]$ & $\begin{array}{l}\text { Precipitation and mid-tropospheric humidity } \\
\text { bias characteristic of the double intertropical } \\
\text { convergence zone }\end{array}$ & Equilibrium climate sensitivity & Credible physical explanation \\
\hline Tsushima et al. [46] & Liquid water path in tropical stratocumulus regime & $\begin{array}{l}\text { Climate warming change of liquid } \\
\text { water path in tropical } \\
\text { stratocumulus regime }\end{array}$ & Credible physical explanation \\
\hline
\end{tabular}

The Primary missing factor column contains a subjective quality remark identifying what we see as the leading deficiency preventing classification as a confirmed emergent constraint

\section{Robustness to Choice of Model Ensemble}

Except in the unlikely case that modeling groups had simultaneously learned of an emergent constraint and substantially removed intermodel spread in the associated predictor, one would expect a confirmed emergent constraint to be manifest in the various collections of climate models (e.g., Coupled Model Intercomparison Project phase 3 (CMIP3) and CMIP5). Indeed, when the same correlations between predictor and predictand appear in different ensembles, it indicates that the physics underpinning the correlations is robust. Note that in the case of snow-albedo feedback discussed above, a nearly identical correlation between predictor and predictand was found in CMIP3 and CMIP5 (Fig. 1), providing further evidence that this is a confirmed emergent constraint.

In the absence of a physical explanation, one must view with suspicion an emergent constraint that appears in a perturbed parameter ensemble of one climate model but not in the structurally more diverse CMIP ensembles, as happened for Klocke et al. [21]. Conversely, if a strong relationship between predictor and predictand can be identified in the CMIP ensembles but not in a perturbed parameter ensemble, it still may become a confirmed emergent constraint. This is only true if it can be shown that the perturbed parameter ensemble fails to exhibit the relationship because variations in a single model's parameters do not adequately vary the physical process underpinning the emergent constraint in the CMIP ensemble.

\section{No Obvious Multiple Influences}

It is difficult to establish the robustness of an emergent constraint for predictors or predictands subject to multiple independent influences. An illustrative example is the case of equilibrium climate sensitivity. This predictand depends on a number of mostly independent feedbacks (and forcing), and each of these contributes to intermodel variance [50]. We do not believe that it is appropriate to seek an emergent 
constraint for climate sensitivity. This is because even if one could find predictors correlated with climate sensitivity, the physical underpinnings of the relationship could only be truly diagnosed through further analyses of individual feedbacks and their individual physical links with the predictor. Moreover, if one takes such a potential emergent constraint at face value, one risks declaring a model that agrees with observations to be realistic even though it has compensating errors in the underlying feedbacks. Another interpretative problem could arise when constraints with different predictors corresponding to distinct influences on the same predictand yield apparently contradictory results. For these reasons, it is most valuable to seek emergent constraints that target individual processes, such as snow-albedo feedback or specific aspects of cloud feedback.

Because global mean cloud feedback depends on independent feedbacks from many cloud types (e.g., high and low clouds, tropical and extra-tropical clouds), we also judge that it is very unlikely that there would be a confirmed emergent constraint for the total cloud feedback. In fact, the requirement that an emergent constraint can only be confirmed if accompanied by a single credible physical explanation suggests a very different scenario: Many emergent constraints will probably be required to ultimately make a difference in a quantity influenced by complex factors, such as overall cloud feedback or the spread in climate sensitivity. In this connection, we believe that the snow-albedo feedback example is also instructive. The physics of the emergent constraint are simple, and this may not be unrelated to the fact that a reduction in spread of the temperature sensitivity of surface albedo in snowcovered regions would only incrementally reduce spread in global climate sensitivity. Consistent with this view, the promising examples we have chosen to highlight in this paper are modest in scope, targeting a minimal number of cloud processes. Also, each of the promising examples shows some potential that further research would reveal a single mechanism generating most of the correlation between the predictor and predictand, leading to a confirmed emergent constraint.

\section{A Comment About Correlation Strength}

Because emergent constraints rely on statistical correlations across a model ensemble, one might be tempted to also consider statistical aspects such as correlation strength, the number of independent models, and insensitivity to outlier models in judging the reliability of an emergent constraint. Of course, without a physical explanation, statistical aspects alone cannot be the basis for emergent constraint reliability, given the ever-present possibility that an emergent constraint could arise through a fortuitous correlation. Indeed, Caldwell et al. [8] have shown that after accounting for the lack of model independence, the distribution of correlation coefficients of a large ensemble of predictors with CMIP5 equilibrium climate sensitivity is indistinguishable from that arising by chance alone. Thus, even large correlations can arise by chance in an ensemble.

At the same time, when the number of independent models is large, high correlations may be strong indicators that a physical explanation does underpin the correlation and is waiting to be diagnosed. In addition, a higher correlation between the predictor and predictand will correspond to a larger spread reduction in the future climate projections when an emergent constraint is found, and models are eventually constrained with it. Thus, a high correlation is desirable and even necessary if the emergent constraint is to have practical value, and the promising examples we discuss below in Examples of Emergent Constraints for Cloud Feedbacks section involve reasonably high correlations.

\section{Examples of Emergent Constraints for Cloud Feedbacks}

Here, we describe recently proposed emergent constraints relating to cloud feedbacks. We begin with a detailed description of three examples that we place in the "promising" category. Following this, we present other emergent constraints that we deem "potential" and then discuss the conditions favoring discovery of new emergent constraints.

\section{Low-Level Cloud Optical Depth}

Building on earlier work [42, 43], Gordon and Klein [12] identified an emergent constraint for the climate change response of the optical depth of low-level clouds, a quantity proportional to a cloud's reflectivity. In this case, the predictor is a model's sensitivity of optical depth to local surface temperature derived from variability at timescales of daily to interannual in a number of different latitudinal bands. The predictand is the relative amount of optical depth change in a model's climate change simulation (see Fig. 2a for the results from middle latitudes). Distinguishing by latitude is necessary. It turns out that the change in optical depth for local temperature increases is generally positive when clouds are cold (for example, at middle and high latitudes), while it only changes by a small amount and is generally negative when the clouds are warm (for example, in the tropics). This differing behavior is present both in the climate change simulations and in the current climate. The increase in low-level cloud optical depth with warming for cold clouds is of limited importance globally but makes an important contribution locally to the negative shortwave cloud feedbacks robustly found in climate models at middle and high latitudes [52].

At middle latitudes, the correlation is quite high. While observations in the form of Fig. 2a are not yet available, the satellite observations from Tselioudis et al. [42] also show the same tendency of a positive temperature derivative at cold temperatures and a weak or negative one at warm 


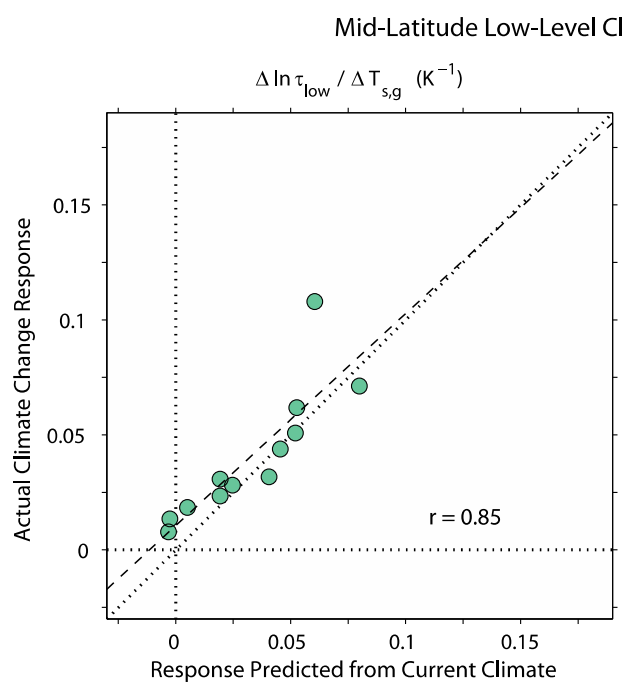

Fig. 2 Relationship in CMIP3 and CMIP5 models between the climate change response of mid-latitude low-level cloud optical depth $\left(\tau_{\text {low }}\right)$ predicted from current climate variability on the abscissa with the actual simulated climate change response on the ordinate (left). More specifically, the "Response Predicted from Current Climate" is equal to the product of the derivative of the natural logarithm of $\tau_{\text {low }}$ with respect to surface air temperature derived from current climate variability with the ratio of simulated mid-latitude $\left(35-55^{\circ}\right)$ to global-mean surface air temperature

temperatures. However, except perhaps at the coldest temperatures, the models have a positive bias relative to these observations (see Fig. 1 of Gordon and Klein [12]). This suggests that models increase cloud optical depth too much with warming. The shortwave effects of low-level cloud optical depth changes outweigh their longwave effects at the top of the atmosphere. Thus, simulated low-level cloud feedbacks resulting from optical depth changes should be less negative.

The increase in optical depth with temperature for cold clouds may stem from fundamental thermodynamics. The adiabatic cloud liquid water content increases appreciably with temperature at cold temperatures [1]. Consistent with this reasoning, the cloud water content of low-level clouds also exhibits "emergent constraint" like behavior (Fig. 2b). At cold temperatures, the multi-model mean temperature derivative of water content derived from current climate variability is close to that predicted by thermodynamics theory assuming adiabaticity [12]. Other factors, such as the change from ice or mixed-phase cloud to more liquid dominant clouds [44], may contribute to intermodel spread and the models' positive bias with respect to observations.

At warm temperatures, the water content-induced change under adiabatic conditions becomes very small. Correspondingly, models do not generally exhibit optical depth increases with warming. The models' small optical depth decreases with warming, and even larger decreases in observations must result from a different mechanism. Taking guidance from models that resolve cloud processes, LES of subtropical stratocumulus suggest the decreases in cloud optical depth with

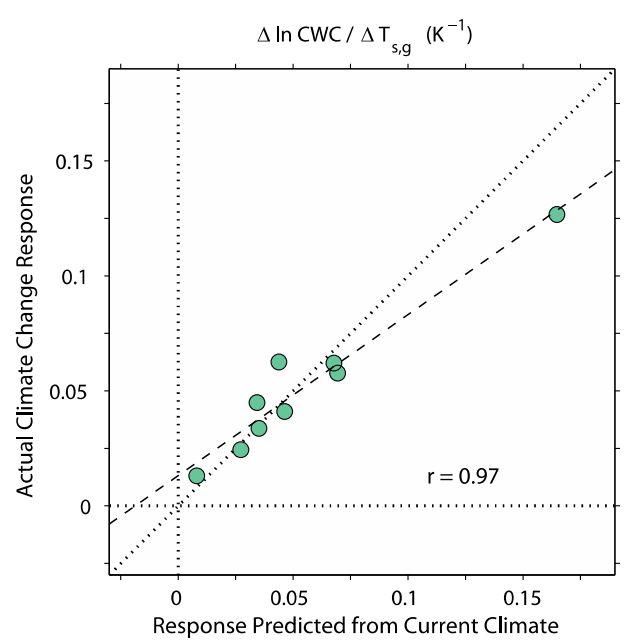

increase $\left(T_{\mathrm{s}, \mathrm{g}}\right)$ in $\mathrm{CO}_{2}$-induced climate warming simulations. The "Actual Climate Change Response" is defined as the mid-latitude change in the natural logarithm of $\tau_{\text {low }}$ actually simulated under $\mathrm{CO}_{2}$-induced climate warming normalized by the increase in global mean surface air temperature. Each green circle displays the value of a single CMIP3 or CMIP5 climate model. The dashed line is the linear regression line, and the dotted line indicates a one-to-one reference line. As in the left panel but for incloud water content (CWC) (right). (Redrawn from [12])

warming are due to cloud thinning. The thinning results from greater efficiency of convective mixing with dry air above the boundary layer upon warming $[6,7,31]$. Climate models may underestimate the observed decrease in optical depth with warming for warm low-level clouds because this mechanism is too weak or absent. At higher latitudes, the absence of this mechanism may also contribute to the models' positive bias to the increase in optical depth with warming. Indeed, to fully accept this as an emergent constraint, future research is needed to isolate the relative roles of adiabatic water content changes, phase partitioning, and convective mixing in contributing to intermodel variations in the temperature sensitivity of optical depth. This is needed to be sure that if a model were tuned to match the observed temperature of sensitivity of optical depth, it would be for the right physical reasons.

\section{Subtropical Marine Low-Level Cloud Cover}

Changes in cloud cover are more important contributors to intermodel spread in cloud feedbacks than changes in cloud optical depth [52]. Studies have consistently found the differing climate responses of subtropical and tropical marine boundary layer clouds to be most responsible for intermodel spread in global mean cloud feedback [4]. For these clouds, $\mathrm{Qu}$ et al. [30] identified a potential path to an emergent constraint through examination of intermodel spread in climate model simulations of low-level cloud cover ( $L C C)$ changes over subtropical subsidence regions, where stratocumulus and cumulus predominate. 
Qu et al. [30] analyzed the LCC changes from twenty-first century climate model simulations with the following framework:

$\Delta L C C=\left.\frac{\partial L C C}{\partial E I S}\right|_{S S T} \times \Delta E I S+\left.\frac{\partial L C C}{\partial S S T}\right|_{E I S} \times \Delta S S T$

In this equation, $\Delta$ refers to the climate change over the twenty-first century in climate model simulations, whereas the partial derivatives are sensitivities of LCC to two large-scale environmental parameters: the estimated inversion strength (EIS, [51]) of the temperature inversion capping the boundary layer and sea surface temperature (SST). These sensitivities are derived from interannual variability in current climate simulations. This model is similar to that used by Gordon and Klein [12] for optical depth changes discussed in a. Low-Level Cloud Optical Depth section, except that it includes an additional environmental parameter, EIS. Nonetheless, it turns out that the EIS parameter is of secondary importance, as most intermodel variance in the twenty-first century LCC change can be explained by the SST term and the SST sensitivity (Fig. 3). It is possible to derive a satellite-based observational estimate for the sensitivity of LCC to SST, using interannual variability over the last 30 years. If the models agreed with these observations, their

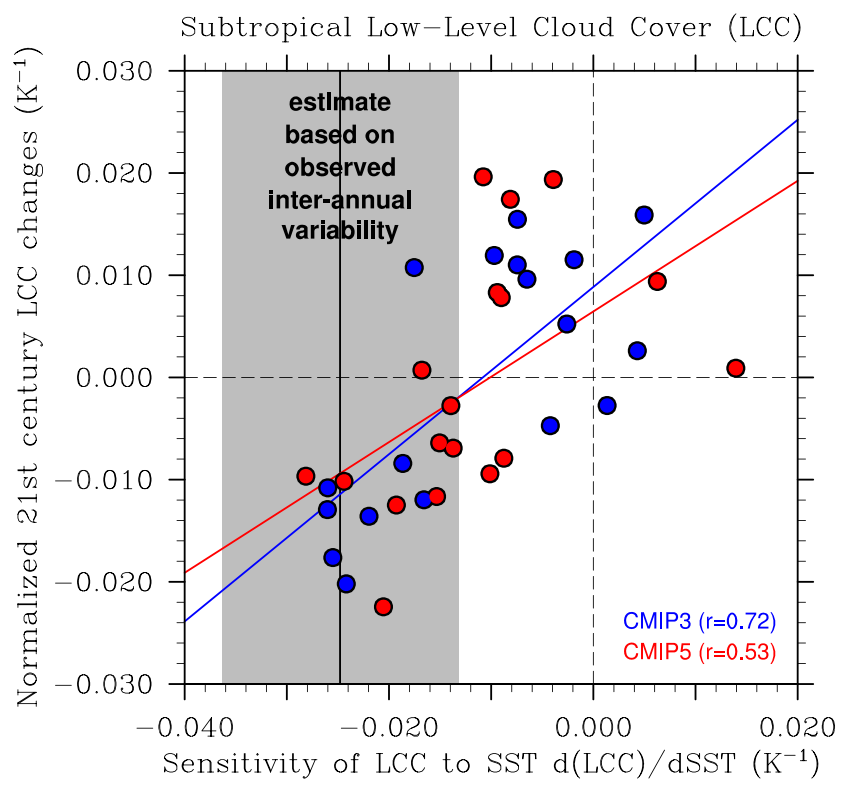

Fig. 3 Scatterplot of the sensitivity of low-level cloud cover $(L C C)$ to sea surface temperature $(S S T)$ on the abscissa versus twenty-first century LCC changes divided by twenty-first century SST changes on the ordinate averaged over the five primary subtropical marine stratocumulus regions. Solid line in each diagram represents a least-squares fit regression line with CMIP3 models color-coded in blue and CMIP5 models in red. Correlation coefficients for each model ensemble are indicated in the lower right corner. Note that the sensitivity of LCC to SST is calculated as a partial derivative holding the value of the estimated inversion strength fixed. The thin vertical line is an observational estimate derived from interannual variability, and the gray shading surrounding this line is the statistical uncertainty of the observed estimate. (Redrawn from [30]) twenty-first century LCC decreases would be in the larger end of the model range, favoring more absorption of solar radiation in the future, and larger climate sensitivities. Earlier work by Bony and DuFresne [2] on the correlation between interannual variability of shortwave cloud radiative effect and SST (their Fig. 4) also hinted that the feedback from subtropical lowlevel clouds should be toward the larger end of model results.

This framework has an underlying assumption: Since the timescales associated with low-level cloud formation and dissipation processes are on the order of hours, low-level clouds must be in statistical equilibrium with large-scale environmental factors whose inherent timescales are order of days or longer [36]. There is ample observational evidence for an association between LCC and EIS [51], including evidence that the direction of causation is primarily from EIS to LCC [19], rather than the reverse. Furthermore, the physical mechanism by which EIS influences LCC is clear: Stronger inversions inhibit the mixing of dry free-tropospheric air into the boundary layer, keeping boundary layer relative humidity and thus LCC higher. However, the physical mechanism by which SST influences LCC (at fixed EIS) needs further research. One possibility is that the LCC sensitivity to SST can be viewed as a surrogate for LCC sensitivity to the vertical gradient in specific humidity from the surface to above the boundary layer, given that variations in this quantity ought to be highly correlated with changes in SST. Indeed, LES analyses suggest that the increased vertical gradient in specific humidity is essential to the positive low-level cloud feedbacks with SST warming. Specifically, with the increased turbulent vertical flux of water within the boundary layer in a warmer climate, less cloud is needed to produce a given amount of mixing across the inversion (all under conditions of no large EIS increases) $[5,7,31]$. If so, this could be the physical

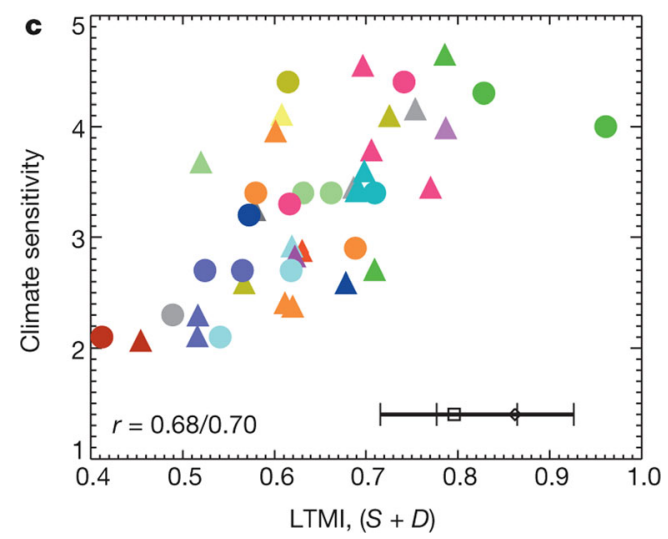

Fig. 4 Scatterplot of the lower tropospheric mixing index (LTMI) on the abscissa and the equilibrium climate sensitivity (on the ordinate) from 43 CMIP3 (circles) and CMIP5 models (triangles). Symbol color identifies modeling center of origin. Linear correlation coefficients are given in the lower left corner of LTMI with the equilibrium climate sensitivity and the total system feedback, respectively. Two observational estimates for LTMI with error bars are shown on the abscissa with central values indicated by the unfilled square and diamond. (From [33]) 
mechanism behind the tendency, seen in LES models and observations, of an LCC decrease with increasing SST, under conditions of fixed EIS.

Qu et al. [30] also showed that a significant reason some models underestimate the SST component of the LCC response is that they rely on so-called Slingo [35]-like cloud parameterizations. These parameterizations predict LCC variations purely in terms of changes in lower tropospheric stability (which is closely related to EIS). They are based on observational evidence that EIS accounts for a significant fraction of LCC variance in the current climate. However, slaving LCC to lower tropospheric stability probably inhibits a model from simulating dependencies on other variables more important for the climate change response $[6,30]$. It may make the most sense to parameterize LCC in terms of local relative humidity or total water relative to saturation and let the resultant sensitivity of the boundary layer physics to environmental parameters determine how LCC will vary.

\section{Lower Tropospheric Mixing and Climate Sensitivity}

Mixing between the boundary layer and the free troposphere plays a central role in low-level cloud variations. So, it is natural to ask if there is a relationship between a climate model's skill in simulating that mixing and its low-level cloud changes associated with climate change. Sherwood et al. [33] follow this line of reasoning. Their emergent constraint also suggests that climate sensitivity is in the upper end of the modelsimulated range (Fig. 4). To measure simulated lower tropospheric mixing, Sherwood et al. [33] consider both mixing at cloud scales resulting from parameterized circulations and mixing resulting from resolved shallow-depth, large-scale circulations. The cloud-scale mixing is measured with an indirect method focusing on the vertical gradient of temperature and moisture between 700 and $850 \mathrm{hPa}$ in the West Pacific warm pool. They argue that greater cloud-scale mixing will result in this layer being less stable, with a smaller decrease in relative humidity with height. Large-scale mixing is measured through the resolved vertical mass flux in circulations encompassing the boundary layer and the lower troposphere. Such shallow circulations have been observed in the eastern tropical Pacific and tropical Atlantic [53], and it is in these regions that Sherwood et al. [33] measure their simulated strength.

Combining somewhat arbitrarily normalized measures of cloud-scale and large-scale lower tropospheric mixing, a lower tropospheric mixing index (LTMI) is defined as the predictor. This index is found to have a positive correlation with models' climate sensitivity as well as their total feedback parameter for the climate system. Observational constraints on LTMI are derived using radiosonde data from selected stations in the West Pacific warm pool for the cloud-scale mixing component and re-analyses produced by two numerical weather prediction centers for the large-scale mixing component. Although the use of re-analyses adds uncertainty, the observational values of LTMI given by Sherwood et al. [33] are in the larger half of model estimates. This suggests the low-level cloud component of climate sensitivity is in the upper half of model results.

The physical explanation offered for this emergent constraint is as follows: In the tropics, both shallow and deep circulations ventilate the boundary layer. The deep circulations are responsible for most global precipitation. The associated latent heat release balances atmospheric radiative cooling. Upon warming, the radiative cooling increase limits the precipitation increase and associated water vapor depletion from the boundary layer by deep circulations to only 2 $4 \%$ per Kelvin [16]. On the other hand, water vapor depletion by shallow cloud-scale circulations is not subject to an energetic constraint, since these circulations do not contribute appreciably to total precipitation. Instead, it increases with the product of the lower tropospheric mixing rate and boundary layer specific humidity. If one assumes that the rate of lower tropospheric mixing remains fixed as the climate warms, then the depletion of water vapor by shallow circulations will increase with boundary layer-specific humidity. This increase follows Clausius-Clapeyron, around $7 \%$ per Kelvin of boundary layer warming.

These arguments imply that as the climate warms, shallow circulations assume a larger role relative to that of deep circulations both in depleting boundary layer water vapor and balancing the addition of water vapor by evaporation from the ocean surface (whose increase is limited to $2-4 \%$ per Kelvin). This leads to a relative humidity reduction in the boundary layer and a low-level cloud decrease. Since the strength of this reduction will be proportional to the amount of lower tropospheric mixing, models with greater lower tropospheric mixing will exhibit a greater decrease in relative humidity and low-level cloud as the climate warms.

Sherwood et al. [33] provide some evidence for this mechanism by examining water vapor tendencies in the few models providing the necessary output. However, a full demonstration of this mechanism is not possible with existing multi-model archives. For example, multi-model diagnostics on the relative amounts of water vapor depletion by shallow and deep convection are not generally available. Also, it would be useful to perform a complete diagnosis of the boundary layer moisture budget in selected climate models and/or construct a toy model to illustrate how the amount of boundary layer drying with climate warming relates to low-level convective mixing strength. Separately, Zhang et al. [54] provide indirect evidence for the small-scale mixing component of the Sherwood mechanism. They configured climate models as singlecolumn models driven by expected large-scale environmental changes for low-level clouds. They found that models with more active shallow convection parameterizations simulate more positive low-level cloud feedbacks. 
In addition, future work for this emergent constraint should demonstrate that LTMI is better related to low-level cloud feedbacks rather than climate sensitivity (following our "no obvious multiple influences" criterion). In fact, Sherwood et al. [33] found the opposite, namely that the correlations of LTMI with the climate changes in low-level clouds were smaller in magnitude than the correlations with climate sensitivity. This is troubling since the physical explanation involves low-level clouds directly and not climate sensitivity, a predictand subject to multiple influences.

\section{Other Emergent Constraints for Cloud Feedbacks}

The three promising emergent constraints discussed above may eventually become confirmed emergent constraints. They each have candidate physical explanations associated with them that are credible, even if work remains to determine which mechanisms are dominant and why. Other emergent constraints related to cloud feedbacks (either directly or indirectly) have also recently appeared in the literature (Table 1). We categorize these constraints to be potential but not yet promising, primarily because they lack the beginnings of a convincing physical explanation. Many also fail our subsidiary criteria by not being robust to the choice of model ensemble or by targeting climate sensitivity, a predictand subject to multiple influences. An exception is that of Zhao [55] who offer a well-developed physical argument based upon the precipitation efficiency of moist convection; this constraint may become promising or even confirmed if it can be shown to apply to CMIP-class ensembles and not solely within a multiphysics ensemble of a single climate model.

It is hard to know a priori how many emergent constraints there could be, given the serendipitously assembled nature of the climate model ensembles. For example, there may be redundancies among some predictors [8], and in this regard, one might expect the constraints of Qu et al. [30] and Sherwood et al. [33] to be redundant. This is because the SST dependence of lowlevel cloud cover might be a surrogate for the amount of cloudscale lower tropospheric mixing and the sensitivity of low-level cloud to changes in the vertical gradient of specific humidity.

\section{Discussion}

An interesting aspect of the three promising emergent constraints presented above is that they all involve low-level clouds. Is there any fundamental reason to expect low-level clouds to exhibit greater propensity for emergent constraint behavior? Perhaps the boundary layer's tendency to react quickly to its local (as opposed to non-local) environmental parameters may make it easier for the long-term response of low-level clouds to be predicted from behavior on short timescales. It may be more difficult to find emergent constraints for other cloud types that respond more strongly to non-local environmental parameters.
Alternatively, the preponderance of emergent constraints for low-level clouds may simply stem from the greater attention given to the feedbacks from low-level clouds; this attention was stimulated most prominently by Bony and DuFresne [2] who clearly demonstrated their major role in contributing to intermodel spread in global mean cloud feedback.

In principle, we do not see why there could not be emergent constraints for other cloud types. For example, the relationship between tropical high-cloud altitude and the vertical profile of clear sky radiative cooling might form the basis for an emergent constraint [15]. However, an emergent constraint for high-cloud altitude may not be detectable if there is no appreciable intermodel spread in its future climate prediction-a necessary condition for the existence of an emergent constraint. In fact, the large spread in low-level cloud feedback may be another reason why it has been relatively easy to find emergent constraints for these clouds.

Finally, we note that two of the three promising emergent constraints involve the covariance of clouds with temperature arising from natural climate fluctuations. They are examples of how concepts associated with the fluctuation-dissipation theorem may be applicable to climate. Aspects of natural cloud variability may be well suited to be predictors for emergent constraints, if clouds are a fast response to their local thermodynamic environment and the influence of cloud-controlling environmental parameters other than temperature, such as inversion strength or atmospheric circulation, can be separately identified. Thus, the covariance of cloud with temperature and other environmental parameters may provide a fruitful pathway to search for emergent constraints in a wide variety of cloud responses. Clouds' fast response to their environment may also make it possible for emergent constraints to be identified in the response of clouds to aerosol perturbations. This appears to be the case for the aerosol cloud lifetime effect [48].

\section{Implications of Emergent Constraints for Climate Models, Observations, and Prediction}

Emergent constraints, if confirmed, have important implications for climate models, climate observations, and climate predictions.

\section{Prioritization of Climate Model Development}

Emergent constraints point to aspects of a model's simulation of current climate that are important for climate prediction. This is particularly helpful in the area of clouds, for it is difficult to know which of their many attributes deserve most attention. With an emergent constraint, modelers can focus on improving the fidelity of the relevant process, knowing that a reduction in intermodel spread will result when it is simulated under anthropogenic forcing. Of course, it may be challenging to use 
guidance from an emergent constraint if the predictor is not specific to a piece of model physics but is the outcome of interactions among many pieces. Furthermore, all of this presumes that model developers will pay attention to emergent constraints. In this regard, it is worth noting that the diversity across models in the snow-albedo response to warming did not narrow in CMIP5 models after the snow-albedo feedback emergent constraint was found in CMIP3 models [13], despite the feedback's key role in shaping the magnitude of simulated climate change in heavily populated Northern Hemisphere land masses [14].

\section{Prioritization of Climate Observations}

Emergent constraints point to potentially observable predictors that might constrain model predictions. Some proposed predictors, such as small-scale and large-scale mixing in shallow-depth atmospheric circulations or the precipitation efficiency of moist convection, may not be easy to measure. Predictors relying on the relationship between variables diagnosed from interannual variability require stable long-term datasets, another practical barrier. A related issue is the size of the observational uncertainty relative to intermodel spread. Only when observational uncertainty does not encompass the entire intermodel spread will projections be constrained. This sets a minimum threshold for observational length and quality. For the three promising emergent constraints discussed in this article, a significant number of climate models lie outside the nominal uncertainty bounds of the observational estimates, implying that intermodel spread in future climate projections can be meaningfully constrained (Figs. 1, 3, and 4). However, these uncertainty estimates deserve greater scrutiny from observational scientists, as it is not clear whether all uncertainty sources have been accounted for.

\section{Narrowing Climate Predictions}

Suppose emergent constraints with a solid physical basis and precise observational estimates are found and applied. How much trust should then be placed in the constrained climate prediction? One might be reluctant to trust the new ensemble with its reduced spread, because some deficiency could be present in all models causing a systematic bias to their predictions. For example, feedbacks from middle-level clouds or tropical anvils associated with mesoscale convective systems may be missed entirely simply because climate models largely fail to simulate these clouds [20, 45]. Nonetheless, the constrained model predictions should be more trustworthy than before, because a source of model error has been identified and reduced. Emergent constraints will never make the models perfect. Instead, they allow limited community resources to be focused on model biases most consequential for climate change. So far, when the emergent constraint technique has been applied to cloud feedbacks, the results have indicated a potential narrowing of uncertainty and a shift in the most likely outcomes. Each of the three promising emergent constraints we discuss here suggests higher values of cloud feedback and hence climate sensitivity.

Acknowledgments The first author thanks Isaac Held for encouraging him to write this article and Bjorn Stevens for inviting him to a workshop that prompted him to organize many of the ideas presented in this article. Both authors thank Robert Pincus for challenging and stimulating discussions. The authors thank Bjorn Stevens and two anonymous reviewers whose comments led to significant improvement in the article. Xin $\mathrm{Qu}$ and Chris Terai are thanked for assistance in figure preparation. The efforts of the authors are supported by the Regional and Global Climate Modeling program of the US Department of Energy's Office of Science under a project entitled "Identifying Robust Cloud Feedbacks in Observations and Models." The efforts of Stephen A. Klein were performed under the auspices of the US Department of Energy by Lawrence Livermore National Laboratory under contract DE-AC52-07NA27344.

Conflict of Interest On behalf of all authors, the corresponding author states that there is no conflict of interest.

\section{References}

1. Betts AK, Harshvardhan. Thermodynamic constraint on the cloud liquid water feedback in climate models. J Geophys Res. 1987;92: 8483-5.

2. Bony S, Dufresne J-L. Marine boundary layer clouds at the heart of tropical cloud feedback uncertainties in climate models. Geophys Res Lett. 2005;32:L20806. doi:10.1029/2005GL023851.

3. Bony S, Webb MJ, Bretherton CS, et al. CFMIP: towards a better evaluation and understanding of clouds and cloud feedbacks in CMIP5 models. Clivar Exchanges. 2011;56(16):20-5.

4. Boucher O, Randall D, Artaxo P, et al. Clouds and aerosols. In: Stocker TF, Qin D, Plattner G-K, Tignor M, Allen SK, Boschung J, Nauels A, Xia Y, Bex V, Midgley PM, editors. Climate change 2013: the physical science basis. Contribution of working group I to the fifth assessment report of the intergovernmental panel on climate change. Cambridge: Cambridge University; 2013. p. 571657.

5. Bretherton CS, Wyant MC. Moisture transport, lower-tropospheric stability, and decoupling of cloud-topped boundary layers. J Atmos Sci. 1997;54:148-67.

6. Bretherton CS, Blossey PN, Jones CR. Mechanisms of marine low cloud sensitivity to idealized climate perturbations: a single-LES exploration extending the CGILS cases. J Adv Model Earth Syst. 2013;5:316-37.

7. Bretherton CS, Blossey PN. Low cloud reduction in a greenhousewarmed climate: results from Lagrangian LES of a subtropical marine cloudiness transition. J Adv Model Earth Syst. 2014;6:91-114.

8. Caldwell PM, Bretherton CS, Zelinka MD, Klein SA, Santer BD, Sanderson BM. Statistical significance of climate sensitivity predictors obtained by data mining. Geophys Res Lett. 2014;41:1803-8. doi:10.1002/2014GL059205.

9. Fasullo JT, Trenberth KE. A less cloudy future: the role of subtropical subsidence in climate sensitivity. Science. 2012;338:792-4.

10. Fermepin S, Bony S. Influence of low-cloud radiative effects on tropical circulation and precipitation. J Adv Mod Earth Sys. 2014;6: 513-26. 
11. Webb MJ, Lock AP, Bretherton CS. The impact of parametrized convection on cloud feedback. Phil Trans R Soc A. 2015;373: 20140414. doi:10.1098/rsta.2014.0414.

12. Gordon ND, Klein SA. Low-cloud optical depth feedback in climate models. J Geophys Res Atmos. 2014;119:6052-65.

13. Hall A, Qu X. Using the current seasonal cycle to constrain snow albedo feedback in future climate change. Geophys Res Lett. 2006;33:L03502. doi:10.1029/2005GL025127.

14. Hall A, Qu X, Neelin JD. Improving predictions of summer climate change in the United States. Geophys Res Lett. 2008;35:L01702. doi:10.1029/2007GL032012.

15. Hartmann DL, Larson K. An important constraint on tropical cloud-climate feedback. Geophys Res Lett. 2002;29:1951. doi: 10.1029/2002GL015835.

16. Held IM, Soden BJ. Robust responses of the hydrological cycle to global warming. J Climate. 2006;19:5686-99.

17. Huber M, Mahlstein I, Wild M, Fasullo J, Knutti R. Constraints on climate sensitivity from radiation patterns in climate models. $\mathrm{J}$ Climate. 2011;24:1034-52.

18. Kiehl JT. Twentieth century climate model response and climate sensitivity. Geophys Res Lett. 2007;34:L22710. doi:10.1029/ 2007GL031383.

19. Klein SA, Hartmann DL, Norris JR. On the relationships among lowcloud structure, sea surface temperature, and atmospheric circulation in the summertime Northeast Pacific. J Climate. 1995;8:1140-55.

20. Klein SA, Zhang Y, Zelinka MD, et al. Are climate model simulations of clouds improving? An evaluation using the ISCCP simulator. J Geophys Res. 2013;118:1329-42.

21. Klocke D, Pincus R, Quaas J. On constraining estimates of climate sensitivity with present-day observations through model weighting. J Climate. 2011;24:6092-9.

22. Knutti R, Meehl GA, Allen MR, Stainforth DA. Constraining climate sensitivity from the seasonal cycle in surface temperature. J Climate. 2006;19:4224-33.

23. Knutti R. Why are climate models reproducing the observed global surface warming so well? Geophys Res Lett. 2008;35:L18704. doi: 10.1029/2008GL034932.

24. Masson-Delmotte V, Schulz M, Abe-Ouchi A, et al. Information from paleoclimate archives. In: Stocker TF, Qin D, Plattner G-K, Tignor M, Allen SK, Boschung J, Nauels A, Xia Y, Bex V, Midgley PM, editors. Climate change 2013: the physical science basis. Contribution of working group I to the fifth assessment report of the intergovernmental panel on climate change. Cambridge: Cambridge University; 2013. p. 383-464.

25. Meehl GA, Covey C, Latif M, Stouffer RJ. Overview of the coupled model intercomparison project. Bull Am Meteorol Soc. 2005;86:89-93.

26. Murphy JM, Sexton DMH, Barnett DN, et al. Quantification of modeling uncertainties in a large ensemble of climate change simulations. Nature. 2004;430:768-72.

27. Ogura T, Emori S, Webb MJ, et al. Towards understanding cloud response in atmospheric GCMs: the use of tendency diagnostics. J Meteorol Soc Jpn. 2008;86:69-79. doi:10.2151/jmsj.

28. Qu X, Hall A. What controls the strength of snow-albedo feedback? J Climate. 2007;20:3971-81.

29. Qu X, Hall A. On the persistent spread in snow-albedo feedback. Clim Dyn. 2014;42:69-81. doi:10.1007/s00382-013-1774-0.

30. Qu X, Hall A, Klein SA, Caldwell PM. On the spread of changes in marine low cloud cover in climate model simulations of the 21st century. Clim Dyn. 2014;42:2603-26. doi:10.1007/s00382-013-1945-z.

31. Rieck M, Nuijens L, Stevens B. Marine boundary layer cloud feedbacks in a constant relative humidity atmosphere. J Atmos Sci. 2012;69:2538-50.

32. Rohling EJ, Sluijs A, Dijkstra HA, et al. Making sense of palaeoclimate sensitivity. Nature. 2012;491:683-91.
33. Sherwood SC, Bony S, DuFresne J-L. Spread in model climate sensitivity traced to atmospheric convective mixing. Nature. 2014;505:37-42.

34. Shukla J, DelSole T, Fennessy M, Kinter J, Paolino D. Climate model fidelity and projections of climate change. Geophys Res Lett. 2006;33:L07702. doi:10.1029/2005GL025579.

35. Slingo JM. A cloud parameterization scheme derived from GATE data for use with a numerical model. Quart J Roy Meteorol Soc. 1980;106:747-70.

36. Stevens B, Brenguier J-L. Cloud-controlling factors: low clouds. In: Heintzenberg J, Charlson R, editors. Clouds in the perturbed climate system. Cambridge: MIT Press; 2009. p. 173-96.

37. Stocker TF, Qin D, Plattner G-K, et al. Technical summary. In: Stocker TF, Qin D, Plattner G-K, Tignor M, Allen SK, Boschung J, Nauels A, Xia Y, Bex V, Midgley PM, editors. Climate change 2013: the physical science basis. Contribution of working group I to the fifth assessment report of the intergovernmental panel on climate change. Cambridge: Cambridge University; 2013. p. 33-115.

38. Su H, Jiang JH, Zhai C, et al. Weakening and strengthening structures in the Hadley circulation change under global warming and implications for cloud response and climate sensitivity. J Geophys Res Atmos. 2014;119:5787-805. doi:10.1002/2014JD021642.

39. Taylor KE, Stouffer RJ, Meehl GA. An overview of CMIP5 and the experiment design. Bull Am Meteorol Soc. 2012;93:485-98.

40. Tian B. Spread of model climate sensitivity linked to doubleintertropical convergence zone bias. Geophys Res Lett. 2015;42: 4133-41. doi:10.1002/2015GL064119.

41. Trenberth KE, Fasullo JT. Simulation of present-day and twentyfirst-century energy budgets of the southern oceans. J Climate. 2010;23:440-54.

42. Tselioudis G, Rossow WB, Rind D. Global patterns of cloud optical thickness variation with temperature. J Climate. 1992;5:1484-95.

43. Tselioudis G, Del Genio AD, Kovari Jr W, Yao M-S. Temperature dependence of low cloud optical thickness in the GISS GCM: contributing mechanisms and climate implications. J Climate. 1998;11: 3268-81.

44. Tsushima Y, Emori S, Ogura T, et al. Importance of the mixedphase cloud distribution in the control climate for assessing the response of clouds to carbon dioxide increase: a multi-model study. Clim Dyn. 2006;27:113-26.

45. Tsushima Y, Ringer MA, Webb MJ, Williams KD. Quantitative evaluation of the seasonal variations in climate model cloud regimes. Clim Dyn. 2013;41:2679-96.

46. Tsushima $Y$, et al. Robustness, uncertainties, and emergent constraints in the radiative responses of stratocumulus cloud regimes to future warming. Clim Dyn. 2015; doi:10.1007/s00382-015-2750-7.

47. Volodin EM. Relation between temperature sensitivity to doubled carbon dioxide and the distribution of clouds in current climate models. Izv Atmos Ocean Phys. 2008;44:288-99. doi:10.1134/ S0001433808030043.

48. Wang M, Ghan S, Liu X, et al. Constraining cloud lifetime effects of aerosols using A-Train satellite observations. Geophys Res Lett. 2012;39:L15709. doi:10.1029/2012GL052204.

49. Watanabe M, Shiogama H, Yokohata T, et al. Using a multi-physics ensemble for exploring diversity in cloud-shortwave feedback in GCMs. J Climate. 2012;25:5416-31.

50. Webb M, Lambert FH, Gregory JM. Origins of difference in climate sensitivity, forcing, and feedback in climate models. Clim Dyn. 2012;40:677-707. doi:10.1007/s00382-012-1336-x.

51. Wood R, Bretherton CS. On the relationship between stratiform low cloud cover and lower-tropospheric stability. J Climate. 2006;19: 6425-32. 
52. Zelinka MD, Klein SA, Hartmann DL. Computing and partitioning cloud feedbacks using cloud property histograms. Part II: attribution to the nature of cloud changes. J Clim. 2012;25:3736-54.

53. Zhang CD, Nolan DS, Thorncroft CD, Nguyen H. Shallow meridional circulations in the tropical atmosphere. J Climate. 2008;21: $3453-70$.
54. Zhang M, et al. CGILS: Results from the first phase of an international project to understand the physical mechanisms of low cloud feedbacks in single column models. J Adv Model Earth Syst. 2013; 5: doi: 10.1002/2013MS000246.

55. Zhao M. An investigation of the connections among convection, clouds, and climate sensitivity in a global climate model. J Climate. 2014;27:1845-62. 